\title{
Research on Parameter Optimization Algorithms of Numerical Control Machining Process for Complex Curved Surface
}

\author{
Mei Tian \\ College of Mechanical Engineering, Jilin Engineering Normal University \\ No. 3050 Kaixuan Road Kuancheng District, 130052 Changchun China \\ 32593829@qq.com
}

Keywords: Complex curved surface; Process parameters; Optimization algorithm; Numerical control

\begin{abstract}
Through the establishment the parameters optimization model of milling machine, the optimal solution of the cutting parameters for complex surface is obtained by using some optimization algorithms for parameter optimization. Based on analyzing the main factors influencing on the milling process, the optimized functions and the corresponding constraint functions are obtained. And in order to improve production efficiency, ensure product quality and reduce production costs, the theoretical optimization results were simulated and processed by software.
\end{abstract}

\section{Introduction}

In today's society, complex surface in mechanical products are used more and more widely. In the processing, the cutting condition is changing, but current $\mathrm{NC}$ machining is with experience of ancestors of the selection of cutting parameters [1] and parameters are the same in the processing process, greatly reduces the production efficiency of NC machine tool, the optimization system is established, the optimization of cutting parameters, can improve production efficiency and reduce production cost.

\section{Optimization Scheme of Milling Parameters}

The optimization of milling parameters is that under certain processing conditions, the optimum combination of cutting parameters to a target or goal selection. Optimization design mainly includes two aspects: one is to establish a reasonable mathematical model, [2] the mathematical model can closely and accurately reflect the optimization problem, is very important for the optimal design. The mathematical model includes: selection of appropriate design variables, establish the target function and constraints. [3] The two is how to obtain the optimal solution of the model, namely for the objective function in a given condition of extreme or optimal value.

\section{Research on Optimization of Process Parameters in NC Milling Process}

Optimal Design Variables. Each NC milling process, which contains a number of path segments, in which the same process parameters can be taken to set the corresponding feed rate $v_{f}$, spindle speed $n$, cutting width $a_{e}$, cutting depth $a_{p}$, the distance traveled by the tool in these paths is $l$, finally, the combination of such a number of path segments together is a path segment combination. Such a combination of the path section constitutes the entire part of the processing process, so the design parameters vector: $[4,5]$

$$
x=\left[n_{1}, v_{f_{1}}, a_{p_{1}}, a_{e_{1}} \cdots n_{i}, v_{f_{i}}, a_{p_{i}}, a_{e_{i}} \cdots n_{n}, v_{f_{n}}, a_{p_{n}}, a_{e_{n}}\right]^{T}
$$

Optimization Objective Function. (1) Maximum productivity objective optimization function Calculation of single piece average production time $t$ : 
$t=t_{0}+t_{m}+t_{c} \frac{t_{m}}{T}$

among: $t_{0} \longrightarrow$ auxiliary time, unit $\mathrm{min} /$ piece;

$t_{m} \longrightarrow$ cutting time, unit $\mathrm{min} /$ piece;

$T \longrightarrow$ tool life, unit min/one;

$t_{c}$ changing time, unit min/ every time;

The highest productivity optimization objective function is:

$t=t_{0}+\sum_{i=1}^{n} \frac{1000 \pi d_{0} l_{i}}{Z v_{i} f_{z i}}+t_{c} \sum_{i=1}^{n} \frac{1000 \pi d_{0} l_{i}}{Z v_{i} f_{z i}} \times\left(\frac{C_{v} d_{0} q_{v}}{v_{i} f_{z}^{y_{v}} a_{p}^{x_{v}} a_{e}^{u_{v}} Z^{p_{v}}}\right)^{-\frac{1}{m}}$

Among them, $c_{v}, y_{v}, q_{v}, u_{v}, k_{v}, m$ constant value coefficient;

$Z-$ cutter tooth number;

$d_{0} \_$cutter diameter, unit $\mathrm{mm}$.

(2) Minimum cost objective optimization function [6]

Single piece average processing cost $\mathrm{C}$ accounting:

$$
\begin{aligned}
& C=M t_{0}+M t_{m}+M t_{c} \frac{t_{m}}{T}+C_{t} \frac{t_{m}}{T}=M \quad \sum_{i=1}^{n}\left(t_{0}+\sum_{i=1}^{n} \frac{1000 \pi d_{0} l_{i}}{Z v_{i} f_{z i}}+\right. \\
& t_{c} \sum_{i=1}^{n} \frac{1000 \pi d_{0} l_{i}}{Z v_{i} f_{z i}} \times\left(\frac{C_{v} d_{0} q_{v}}{v_{i} f_{Z}^{y_{v}} a_{p}^{x_{v}} a_{e}^{y_{v}} Z^{p_{v}}} k_{v}\right)^{-\frac{1}{m}}+c \times \sum_{i=1}^{n}\left(\frac{1000 \pi d_{0} l_{i}}{Z v_{i} f_{z i}} \times\left(\frac{C_{v} d_{0} q_{v}}{v_{i} f_{z}^{y_{v}} a_{p}^{x_{v}} a_{e}^{u_{v}} Z^{p_{v}}} k_{v}\right)^{-\frac{1}{m}}\right)
\end{aligned}
$$

Object Constraint Function. (1) Main cutting force constraint [7]

$$
F_{C}=K_{F_{C}} \frac{9.81 C_{P} a_{P}^{x_{F}} f_{z}^{y_{F}} a_{e}^{u_{F}}\left(\pi d_{0}\right)^{w_{F}}}{d_{0}^{q_{f}}(60 v)^{w_{F}}}-F_{\text {max }} \leq 0
$$

Form in, When the cutting conditions are changed, $K_{F_{C}}$ is the correction factor of milling Force; $C_{P}$ is the cutting force coefficient; $a_{e}$ is the cutting width; $a_{p}$ is the cutting Depth; $f_{z}$ is the feed per tooth; $d_{0}$ is the milling cutter diameter; $\mathrm{Z}$ is the tooth number of milling cutter; $\mathrm{V}$ is the cutting speed of milling cutter, Other as index.

(2) Output power of machine tool [8]

$P=\frac{F_{C} v}{1000}-\eta P_{\max } \leq 0$

among: $\quad \eta \quad$ Efficiency index of machine tool

$P_{\max } \longrightarrow$ Maximum output power of machine tool

(3) Feed rate

$$
\begin{aligned}
& v_{1}=\frac{60 v f_{z} Z}{\pi d_{0}}-v_{f \text { min }} \leq 0 \\
& v_{2}=v_{f \text { max }}-\frac{60 v f_{z} Z}{\pi d_{0}} \leq 0
\end{aligned}
$$


The $v_{f \text { min }}$ and $v_{f \text { max }}$ in the formula is the minimum and maximum feed rate of the machine tool.

(4) Spindle speed

$$
\begin{aligned}
& n_{1}=n_{\min }-\frac{60 v}{\pi d_{0}} \leq 0 \\
& n_{2}=\frac{60 v}{\pi d_{0}}-n_{\text {max }} \leq 0
\end{aligned}
$$

The $n_{\min }$ and $n_{\max }$ in the formula are the lowest and the highest spindle speed of the machine.

(5) Surface roughness

$$
R=R_{a}-R_{a \max } \leq 0
$$

The surface roughness obtained by $R_{a}$ in the formula is obtained, $R_{a \max }$ is machined surface roughness as required by machining. [9]

Model of Optimization Mathematical. In summary, the cutting parameter optimization problem to type:

$$
\left\{\begin{array}{l}
\min F\left(v_{i}, f_{z i}\right) \\
s_{n} t_{n}\left\{\begin{array}{l}
F_{i} \leq F_{f \text { max }} \\
P_{i} \leq P_{\text {max }} \\
n_{\text {min }} \leq \frac{60 v_{i}}{\pi d_{0}} \leq n_{\text {max }} \\
v_{f \text { min }} \leq \frac{60 v_{i} f_{z i} z}{\pi d_{0}} \leq v_{f \max } \\
R_{a} \leq R_{a \max }
\end{array} \quad(i=1,2, \cdots n)\right.
\end{array}\right.
$$

\section{Optimization Example}

The beverage bottle bottom as shown in Fig. 1, for example, the application of CAXA manufacturing engineer on the simulation processing(as shown in Fig. 2). Blank material for plastic, the size is $80 \mathrm{~mm} * 30 \mathrm{~mm} * 80 \mathrm{~mm}$, processing on the XD-40A CNC milling machine, ball milling cutter with $\phi 8$ cutter used for machining, the feed rate is $1500 \mathrm{~mm} / \mathrm{min}$, spindle speed is 1800 $r / \mathrm{min}$, the results of the optimization parameters are shown in table 1 .

Table 1 Optimization results of process parameters

\begin{tabular}{cccc}
\hline & $\begin{array}{c}\text { processing time } \\
{[\mathrm{s}]}\end{array}$ & $\begin{array}{c}\text { processing cost } \\
{[\text { yuan] }}\end{array}$ & $\begin{array}{c}\text { surface roughness } \\
\mathrm{R}[\mu \mathrm{m} \backslash\end{array}$ \\
\hline $\begin{array}{c}\text { before } \\
\text { optimization }\end{array}$ & 5282 & 67 & 0.67 \\
\hline $\begin{array}{c}\text { after } \\
\text { optimization }\end{array}$ & 5165 & 62 & 0.16 \\
\hline
\end{tabular}




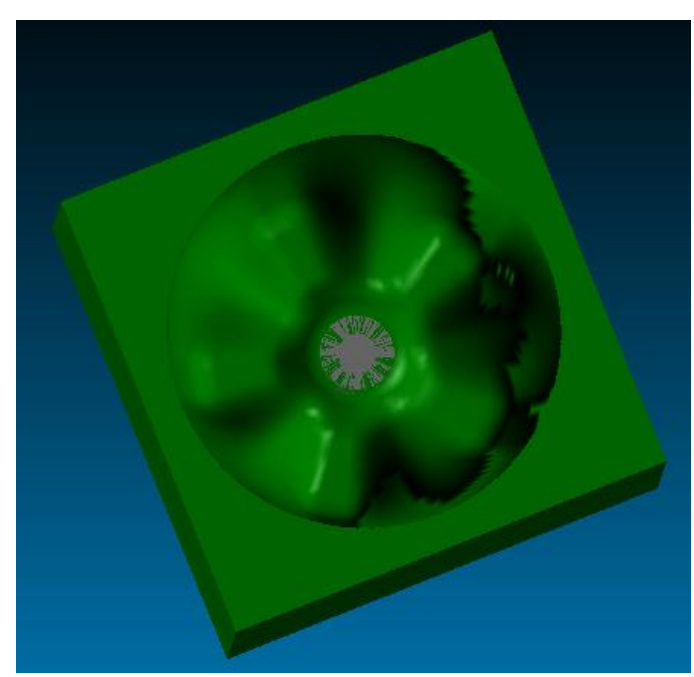

Figure 1. Beverage bottle bottom part drawing

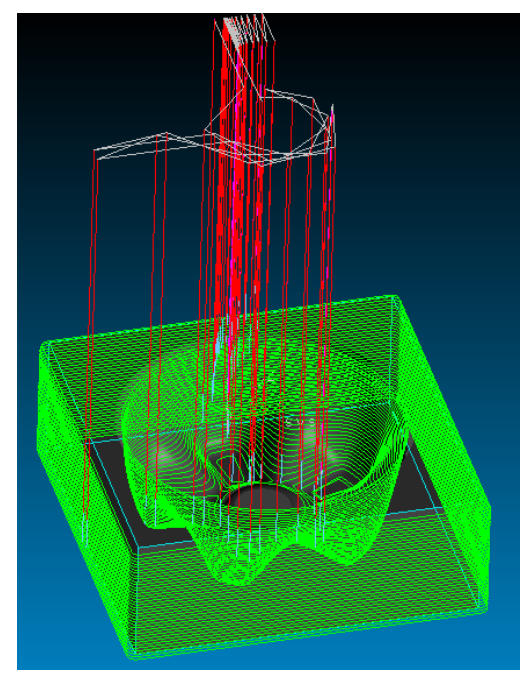

Figure 2. Simulation process

Compared with the above data, processing parameters optimization, the completion time of all the process from the original 5282s to 5165s, the production efficiency has been improved. Processing costs from the original 67 yuan to 62 yuan, reducing the cost of processing. The surface roughness was reduced from $0.67 \mu m$ to $0.16 \mu \mathrm{m}$, and the surface quality was improved.

\section{Conclusion}

On the foundation of $\mathrm{NC}$ milling model and of NC milling parameter optimization research, mainly on the spindle speed, feed rate, the cutting width is used to optimize the parameters of,[10] using optimization simulation technology to optimize the processing procedures, ways to improve the machining efficiency. Put forward the optimization method of NC milling, milling parameters optimization mathematical model is established and comprehensive, and find out the optimal solution, and give examples of optimization.

\section{Acknowledgement}

This work was financially supported by the Research and Development Project of Jilin Engineering Normal University.

\section{References}

[1] Y.J. Chen and X.T. Chen: Modular Machine Tool \& Automatic Manufacturing Technique, (2013) No.3, p96. (In Chinese)

[2] J.K. Yang: Management and technology of small and medium sized enterprises,(2014)No.06, p.248.(In Chinese)

[3] Q. Huang and C.J. Gao: China Mechanical Engineering, Vol. 25 (2014) No.7, p.857.

[4] K. Ren, W.H. Chen, J. Pan, H.G. Chen and S.D. Lin: Journal of Mechanical Engineering, Vol. 46 (2010) No.15, p.155. (In Chinese)

[5] C.H. Yu: Occupation, (2013) No.26, p.248.(In Chinese)

[6] J.G. Yang, Y.Q. Ren, W.B. Zhu, M.L. Huang and Z.H. Pan: Chinese Journal of Mechanical Engineering, Vol. 39 (2003) No.3, p.81. (In Chinese)

[7] J.F. Ji, L.S. Zhou, L.L. An and C. Zhang: Journal of Chongqing University, Vol.33, p.37. (In Chinese)

[8] B. Yan, A. P. Xu, D. W. Zhang and T. Huang: Chinese Journal of Mechanical Engineering, 
(2002) No.02, p.160.(In Chinese)

[9] M.Q. Sun and Z.Y. Weng: Tool technology, vol.40 (2006) No.9, p7. (In Chinese)

[10] R.Q. He, S.J. Yan and Y.F. Zhou: Machine Tool \& Hydraulics, (2006) No.9, p80. (In Chinese) 